* Acadêmico do décimo período das FAAT-Ensino/ Universidade Positivo. Estagiário no escritório Fábio Brasilino Sociedade Individual de Advocacia. jeangcapeli@gmail. com.

** Pós-Doutorando pela Universitàdegli Studi di Messina - Itália. Doutor em Direito FADISP. Mestre em Direito Negocial - UEL. Especialista em Direito Internacional e Econômico - UEL. Membro do Instituto de Direito Privado. Membro do BRASILCON. Professor e Parecerista. UNOPAR. professorbrasilino@gmail.com.

\section{A teoria do deSVio PROdUtivo e A PROTEÇÃo doS DIREITOS DA PERSONALIDADE DO CONSUMIDOR}

\author{
Product DEVIATION THEORY AND THE PROTECTION TO THE \\ CONSUMER`S PERSONALITY RIGHTS
}

Jean Guilherme Capeli Domingues* Fabio Ricardo Rodrigues Brasilino **

Como citar: DOMINGUES, Jean Guilherme Capeli. BRASILINO, Fabio Ricardo Rodrigues. A teoria do desvio produtivo e a proteção dos direitos da personalidade do consumidor. Revista do Instituto de Direito Constitucional e Cidadania, Londrina, v. 3, n. 1, p. 190-208, jan/jun. 2018.

https://doi.org/10.48159/revistadoidcc.v3n1.domingues.brasilino

Resumo: O Estado Democrático de Direito tem por objetivos a construção de uma sociedade livre, justa e solidária, a erradicação da pobreza e a redução das desigualdades. Para tanto, é fundamental a participação do Estado lato sensu, por meio de políticas que possibilitem a convivência harmoniosa entre capital e direitos sociais, seja por meio de políticas públicas e/ou legislativas, pois o Direito visa proteger interesses, e são estes que ligam as pessoas às coisas. A defesa do consumidor surge como um direito fundamental e a sua proteção tem que ir além das questões patrimoniais. O recorte metodológico da pesquisa tem como núcleo analisar a teoria do desvio produtivo e a proteção dos direitos da personalidade do consumidor. Para tanto, o presente estudo se vale de uma metodologia técnicoformal, por meio do método dialético e do procedimento monográfico, que consiste na análise das normas (lato sensu), jurisprudência pátria e estrangeira e doutrina relativa à temática. Analisa o desvio produtivo e afere a importância do tempo na contemporaneidade. Estuda a importância das questões existência para assegurar a dignidade da pessoa humana. Verifica a natureza do dano em relação ao desvio produtivo. Conclui que atualmente é inegável a importância do tempo na contemporaneidade e por isso deve ser tutela pelo direito, o fornecedor quando não observa o seu dever de prestar um serviço de qualidade comete um dano ao consumidor, passível de compensação por meio da responsabilidade civil (dano moral).

Palavras-chave: Teoria do desvio produtivo. Direitos existenciais. Direitos da personalidade. Defesa consumidor. 


\begin{abstract}
Democratic State has for goals building a free, just and supportive society and also to eradicate poverty and reduce social inequalities. To pursue such goals State participation is a must developed through policies that make harmony between finances and social rights possible. Consumer's legal defense rises up as a fundamental right and it's protection needs to go far above patrimonial matters. The methodology of this essay has the purpose of analyzing the product deviation theory and the protection to consumer's personality rights. To achieve this aim a formal-technician and dialectic methods have been selected along the study of legal norms applied to the subject and national and foreigner judicial precedents. It also verifies the nature of the harm caused by the product deviation. Finally, our conclusion is that when the provider doesn't' fulfill it's obligation providing a satisfying service or product a legal harm is produced against the consumer, arising the need of compensation in favor of the consumer by civil liability (moral damage).
\end{abstract}

Keywords: Product Deviation Theory. Existencial Rights. Personality Rights. Consumer's Legal Defense. 


\section{INTRODUÇÃO}

O presente estudo analisará a teoria do desvio produtivo e como ela surge enquanto ferramenta para a proteção dos direitos dos consumidores. O que se demonstrará é que o fornecedor ao não prestar um serviço de qualidade, seja de forma intencional ou não, ofende todo o sistema jurídico de defesa do consumidor. Essa ofensa deve ser punida, sob pena de ferir normas constitucionais relacionadas a temática. Assim, uma vez aferido o dano esse deve ser compensado, sendo o dano moral importante instrumento para tanto.

Para chegar a essa conclusão, o presente artigo será dividido em quatro capítulos.Para tanto, o presente estudo se vale de uma metodologia técnico-formal, por meio do método dialético e do procedimento monográfico, que consiste na análise das normas (lato sensu), jurisprudência pátria e estrangeira e doutrina relativa à temática. A preocupação do primeiro capítulo será trabalhar o desvio produtivo e a importância do tempo da na contemporaneidade. Na sequência, o segundo capítulo, terá como preocupação discorrer sobre a importância das atividades existenciais às pessoas. O terceiro capítulo tem como foco analisar quais são as consequências da inobservância, por parte do fornecer do dever de bom atendimento. No quarto capítulo, a teoria do desvio produtivo será estudada para, por fim, no quinto e último capítulo analisar qual é o dano e sua natureza.

A contribuição do presente estudo é trazer discussões acerca do tempo na contemporaneidade e as consequências jurídicas do desrespeito, por parte do fornecedor, do dever de prestar o serviço de forma adequada.

\section{DO DESVIO PRODUTIVO E A IMPORTÂNCIA DO TEMPO NA CONTEMPORANEIDADE}

É inegável a importância do tempo na contemporaneidade, assim deve ser reconhecido como um bem a ser tutelado pelo Direito. Nessa perspectiva, surge a discussão quanto ao chamado desvio produtivo. Marcos Dessaune, principal propulsor da teoria no Brasil, conclui que desvio produtivo "é um evento danoso induzido pelos fornecedores que, de modo abusivo, se eximem da sua responsabilidade pelos problemas de consumo que criam no mercado"1.

No mesmo sentido, os autores Rene Edney Soares Loureiro e Héctor Valverde Santana defendem que "nas relações de consumo, verificam-se constantes abusos dos fornecedores, como a não prestação de serviços ou má prestação de serviços, fatores esses que ocasionam uma perda injusta, desproporcional e desarrazoada de tempo dos consumidores". Tudo isso faz como que eles sejam "forçados a deixar seus compromissos diários, profissionais, de lazer, de descanso, de estar na companhia de familiares ou da pessoa amada para buscar uma solução efetiva e idônea dos pro-

1 DESSAUNE, Marcos. Teoria aprofundada do desvio produtivo do consumidor: o prejuízo do tempo desperdiçado e da vida alterada. 2. ed. Vitória, 2017. p. 25. 
blemas afetos às relações de consumo"2. O que se verifica é a perda do tempo por culpa exclusiva do fornecedor que não prestou o serviço de forma adequada.

Conforme outrora exposto o tempo é um bem jurídico na contemporaneidade, portanto ao fornecedor é imposto o dever de bom atendimento, respeitando os direitos existenciais das pessoas. Ao não observar tais direitos, acaba subtraindo indevidamente o tempo disponível ao consumidor e interferindo diretamente em seus direitos da personalidade.

O "tempo" é um substantivo masculino que remete a ideia de "série ininterrupta e eterna de instantes", ou seja, trata-se de um período contínuo com a noção de presente, passado e futuro ${ }^{3}$. A definição de tempo é demasiada controvertida e abrangente,no entanto, a título de exemplo, é possível destacar sua importância até mesmo nas mais diversas relações jurídicas, vez que nessa seara "o tempo é considerado parâmetro para criação, extinção, modificação, aquisição e exercício de direitos" $"$

Antônio Dinei Aguiar de Araújo Junior e Angel Tomas Castroviejo sustentam que:

$\mathrm{Na}$ ciência jurídica deparamos com o fator tempo logo em seus fundamentos. (...) $\mathrm{O}$ tempo tem grande influência na aquisição e extinção dos direitos, sendo fundamental para o estudo da prescrição e decadência. Até este ponto, o tempo é um mero coadjuvante na ciência jurídica; quando nos aprofundamos no direito processual constatamos que o tempo se torna fundamental para o exercício do direito. Ao fixar prazos para as partes, a lei faz do tempo uma ferramenta jurídica de garantia de um devido processo legal. ${ }^{5}$

Ainda nesse enfoque, salienta-se que o tempo também conserva crucial importância para o Direito Penal, haja vista que, sem prejuízo de outros fatores, é empregado justamente como parâmetro de pena.

Ademais, cita-se o direito fundamental à razoável duração do processo, previsto no artigo $5^{\circ}$, LXXVIII, da Constituição Federal, intrinsicamente ligado à ideia de tempo e celeridade.

Todavia, conforme expõe Lee Cockerell, sua importância não diz respeito apenas ao Direito, sendo pertinente na vida de modo geral:

Uma das coisas mais importantes que você pode fazer é parar para refletir profundamente sobre como gasta seu tempo, como não gasta seu tempo e onde deveria gastar seu tempo, não só no trabalho, mas em todos os âmbitos da sua vida. A qualidade de vida depende diretamente de como e onde você gasta seu

2 LOUREIRO, Rene Edney Soares; SANTANA, Héctor Valverde. Dano moral e responsabilidade objetiva do fornecedor pela perda do tempo produtivo do consumidor. Revista de Direito do Consumidor, São Paulo, v. 106, ano 25, p. 357-378, jul.-ago. 2016. p. 359.

3 Conforme dicionário Priberam. Disponível em: <https://www.priberam.pt/dlpo/TEMPO>. Acesso em 30 out. 2017.

4 GUGLINSKI, Vitor. O dano temporal e sua reparabilidade: aspectos doutrinários e visão dos tribunais. Revista de Direito do Consumidor, v. 99, p. 125 - 156, maio-jun. 2015. p. 128.

5 ARAUJO JUNIOR. Antônio Dinei Aguiar; CASTROVIEJO, Tomas Angel. A influência do tempo no sistema jurídico. Disponível em: $<\mathrm{https}$ ://uspdigital.usp.br/siicusp/ cdOnlineTrabalhoVisualizarResumo?numeroInscricaoTrabalho=3456\&numeroEdicao=18<https://uspdigital.usp. $\mathrm{br} /$ siicusp/cdOnlineTrabalhoVisualizarResumo?numeroInscricaoTrabalho=3456\&numeroEdicao $=18>$. Acesso em 30 out. 2017. 
tempo. Hoje em dia, praticamente todo mundo se sente oprimido por todas as demandas que ocupam seu tempo, demandas que nunca foram tão intensas quanto agora. A maioria das pessoas precisa render mais no trabalho, e isso, somado a todas as responsabilidades fora do escritório, pode ser tão estressante que as pessoas simplesmente sentem que não têm controle sobre a própria vida. É um sentimento terrível. Não é o estresse que nos mata, mas sim a angústia de sentir que perdemos o controle ${ }^{6}$

De fato, quando se fala em controle, sobretudo o que se busca é uma otimização do tempo, talvez sendo este o maior desejo contemporâneo.Ilustrando a importância do tempo, Vitor Vilela Guglinski, aproveitando-se de mitologia nórdica narrada por Thomas Bulfinch, traz a seguinte noção:

A demora e o atraso são servos da morte. Ao menos é assim na mitologia nórdica, que, dentre suas muitas fábulas, narra a descendência de Loki, divindade dedicada a caluniar os deuses e disseminar todo tipo de fraudes e maldades. Entre os três filhos de Loki está Hela (a Morte). Thomas Bulfinch, ao descrever Hela, assinala que 'a Fome é sua mesa, a Indigência sua faca, a Demora sua serva, o Atraso seu empregado, o Precipício seu liminar (...)' Transportando a narrativa mitológica para o mundo real, não haveria nenhum exagero em se afirmar que há relativa verdade naqueles contos, já que o tempo é um fator umbilicalmente ligado à vida do homem. A vida possui um tempo. Todos têm um 'prazo de validade" ${ }^{7}$

Nessa linha, Marcos Dessaune, utilizando-se dos ensinamentos de Ronaldo Mourão, fez constar em sua obra que:

O tempo é o suporte implícito de todo pensamento de gênese, de origem, de história e de destino. Ele é o principal responsável pelas inquietações da vida humana. Toda evocação de tempo está carregada de angústias, de tristezas, de fantasmas, de esperanças ${ }^{8}$.

O autor, utilizando-se do pensamento do filósofo francês Bernard Piettre, chega a sustentar que "o tempo é o domínio de toda preocupação existencial". Com isso defende, em sua obra, que o tempo constitui riqueza individual, não sendo justo e tampouco digno, sob um ponto de vista humano, aceitar que seja transformado em um bem sempre em falta, tal como se constata atualmente ${ }^{10}$.

Isso pois, o tempo é o que permite o fazer. Seja qual for o viés, o tempo é sempre relevante. $\mathrm{Na}$ contemporaneidade, então, em que cada vez mais as tarefas se acumulam no cotidiano, não é

6 COCKERELL, Lee. A magia do gerenciamento do tempo. Tradução de Cristina Yamagami.São Paulo: Benvirá, 2016. p. 22

7 GUGLINSKI, Vitor. O dano temporal e sua reparabilidade: aspectos doutrinários e visão dos tribunais. Revista de Direito do Consumidor, v. 99, p. 125 - 156, maio-jun. 2015. p. 128.

8 DESSAUNE, Marcos. Teoria aprofundada do desvio produtivo do consumidor: o prejuízo do tempo desperdiçado e da vida alterada. 2. ed. Vitória, 2017. p. 149.

9 DESSAUNE, Marcos. Teoria aprofundada do desvio produtivo do consumidor: o prejuízo do tempo desperdiçado e da vida alterada. 2. ed. Vitória, 2017. p. 149.

10 DESSAUNE, Marcos. Teoria aprofundada do desvio produtivo do consumidor: o prejuízo do tempo desperdiçado e da vida alterada. 2. ed. Vitória, 2017. p. 154. 
difícil notar a relevância do tempo. Traduzindo essa realidade, expõe Leonardo de Medeiros Garcia que:

Muitas situações do cotidiano nos trazem a sensação de perda de tempo: o tempo em que ficamos 'presos' no trânsito; o tempo para cancelar a contratação que não mais nos interessa; o tempo para cancelar a cobrança indevida do cartão de crédito; a espera de atendimento em consultórios médicos etc ${ }^{11}$.

Outrossim, conforme pontua Rene Edney Soares Loureiro e Héctor Valverde Santana:

Há que se observar que atualmente o tempo está muito curto para todos. Os inacabáveis problemas e compromissos do dia a dia acarretam a certeza de que as vinte e quatro (24) horas de um dia são, indiscutivelmente, insuficientes. Segundo dados do Instituto Brasileiro de Geografia e Estatística (IBGE), a expectativa de vida dos homens e mulheres que nascem no Brasil subiu e atualmente é de 75 anos, 10 meses e 24 dias, ou seja, 27338 dias para a resolução de todos os afazeres. Entretanto, esse tempo é preenchido com nossos compromissos diários e responsabilidades pessoais, restando, assim, pouco tempo livre ${ }^{12}$.

Portanto, não se olvide que o tempo é um bem jurídico precioso para o ser humano, bem este que deve ser tutelado, vez que é inerente à dignidade humana, nos termos do artigo $1^{\circ}$, III, da Constituição Federal e, no que tange o tema em estudo, à liberdade do consumidor de modo geral.

Nesse Sentido é a fundamentação do Desembargador Jones Figueiredo Alves, do Tribunal Judiciário do Estado de Pernambuco (TJ-PE), quando proferiu voto em decisão que condenou uma instituição financeira a indenizar consumidora por dano moral, primordialmente pela subtração indevida do tempo:

A visão eclesiástica do tempo diz-nos que tudo tem o seu tempo determinado e há tempo para todo propósito debaixo do céu: há tempo de nascer e tempo de morrer; tempo de chorar e tempo de rir; tempo de abraçar e tempo de afastar-se; tempo de amar e tempo de aborrecer; tempo de guerra e tempo de paz. (...) Do vilipêndio do tempo, porém, caso é saber que, na hipótese, esse tempo não é apenas desperdiçado, pela perda do próprio tempo, faculdade que é dada ao homem exercitá-lo nas circunstâncias do tempo e dos interesses da vida. Nessa segunda hipótese, a do vilipêndio, o tempo é subtraído violentamente do homem por terceiro, que rouba, sutilmente, a vida do outro, por atitudes de apreensão abusiva do tempo (...). A questão é de extrema gravidade e não se pode admiti-la, por retóricas de tolerância ou de condescendência, que sejam os transtornos do cotidiano que nos submetam a esse vilipêndio de tempo subtraído de vida, em face de uma sociedade tecnológica massificada, impessoal e disforme, onde nela as pessoas possam perder a sua própria individualidade, consideradas que tornem apenas usuários números em bancos informatizados de dados. O banco da vida é diferente: tem os seus dados de existência contados em segundos, minutos e horas, onde cada dia é também medida divina do tempo $(\ldots)^{13}$

11 GARCIA, Leonardo de Medeiros. Direito do consumidor: Código comentado e jurisprudência. 7. ed. Niterói: Impetus, 2011.

12 LOUREIRO, Rene Edney Soares; SANTANA, Héctor Valverde. Dano moral e responsabilidade objetiva do fornecedor pela perda do tempo produtivo do consumidor. Revista de Direito do Consumidor, São Paulo, v. 106, ano 25, p. 357-378, jul.-ago. 2016. p. 359.

13 Disponível em: [http://s.conjur.com.br/dl/decisão-tribunal-de-justiça-pernambuco.pdf]. Acesso em: 25/05/2017 
Ademais, o tempo é essencial para um razoável exercício das atividades existenciais da pessoa humana, conforme se abordará no tópico a seguir, sendo conveniente introduzir o tema com as explanações de Vitor Vilela Guglinski:

(...) o tempo pode ser analisado sob duas perspectivas: (i) da sua utilidade e (ii) do seu uso livre. Sob o ângulo da utilidade, demanda-se disponibilidade de tempo para a execução de variadas tarefas do cotidiano, para o cumprimento de obrigações e para o trabalho. (...) Por outro lado, o tempo livre seria aquele dedicado a se fazer o que se quer, sem vínculos ou predeterminações. É o tempo que não está ligado a tarefas ou obrigações ${ }^{14}$.

Portanto, o tempo é fator que transcende a perspectiva da utilidade, vez que viabiliza o exercício de atividades de entretenimento de igual modo cruciais para o atingimento ou manutenção da dignidade humana.

\section{DAS ATIVIDADES EXISTENCIAIS DA PESSOA HUMANA}

O Direito, por certo, é um mecanismo de pacificação social, significando dizer que visa promover uma coexistência harmônica entre os indivíduos em sociedade. Cada vez mais há a humanização das decisões pacificadoras dos litígios. Tal fato se dá pela tendência global a modificar as estruturas dos meios de produção e utilização dos bens em prol de um bem-estar coletivo. Tratase de fazer uma releitura do próprio conceito de propriedade. Essa tendência à funcionalização social da propriedade parte do pressuposto de um poder-dever do proprietário de funcionalizar sua propriedade não apenas de acordo com seus anseios particulares, mas sim com base em uma função social fundamentada no bem comum e reconhecer os direitos existenciais.

O princípio da dignidade da pessoa humana surge no atual ordenamento jurídico brasileiro como centro norteador, portanto todas as relações, inclusive as privadas, devem tê-lo nessa perspectiva. Há uma aplicação principiológica, e com isso a dimensão patrimônio e dignidade agrega um novo fato à função social. Assim, a funcionalização do patrimônio ocorre quando a função social e a dignidade humana encimam o direito de propriedade, o que faz com que os bens não sejam tratados como um fim, mas sim como um meio de preservar a condição digna de seu donatário.

O princípio da dignidade pessoa humana possui conteúdo demasiado abrangente, certamente agasalhando as atividades existenciais do indivíduo, Marcos Dessaune elucida que:

O homem é um ser em ação, que elabora planos e dirige o seu movimento, com o objetivo de alcançar determinados fins. A escolha desses fins não é feita por acaso, mas em função do que o homem considera importante à sua vida, de acordo com os valores que elege ${ }^{15}$.

Cada indivíduo, no decorrer de sua existência, por meio de suas constantes escolhas cotidianas, vai desenvolvendo sua personalidade e norteando um caminho que, a seu critério, entende 14 GUGLINSKI, Vitor. O dano temporal e sua reparabilidade: aspectos doutrinários e visão dos tribunais. Revista de Direito do Consumidor, v. 99, p. 125 - 156, maio-jun. 2015. p. 135.

15 DESSAUNE, Marcos. Teoria aprofundada do desvio produtivo do consumidor: o prejuízo do tempo desperdiçado e da vida alterada. 2. ed. Vitória, 2017. p. 192. 
ser promovente da dignidade. Claro que nem todos possuem projeto de vida bem definido, mas evidentemente se guiam e exercem suas preferências rotineiras, em que também se identifica o conceito lançado. De toda forma, o indivíduo, uma vez livre, capaz e dotado de razão, tende a investir nas opções que darão sentido a sua existência.

As atividades existenciais humanas, em que pese subjetivas, podem ser identificadas no texto constitucional. Por exemplo, o estudo, tutelado no artigo 205 da Constituição Federal; o trabalho, que não obstante figurar como fundamento constitucional (art. $1^{\circ}, \mathrm{IV}$ ), é referenciado em diversas passagens. ${ }^{16} \mathrm{O}$ descanso, nos termos do artigo $7^{\circ}$, XIII, XIV, XV e XVII; o lazer, conforme o artigo $6^{\circ}, 217, \S 3^{\circ}$ e 227; o convívio social, a teor do artigo $5^{\circ}$, VI, XVI, artigo 203, IV, artigo $226, \S \S 3^{\circ}, 4^{\circ}$ e $8^{\circ}$, artigo $227, \S 1^{\circ}$, dentre outros; os cuidados pessoais, consoante os artigos $6^{\circ}$ e 196; e o próprio consumo, à luz dos já estudados artigos $5^{\circ}$, XXXII e 170, V; etc.

Desse modo, o dano existencial está intimamente ligado primordialmente ao princípio da dignidade da pessoa humana, mas também mantêm fiel relação com diversos outros direitos instituídos pela Constituição Federal de 1988.

É possível afirmar que o dano existencial consiste em uma alteração prejudicial nas relações do indivíduo interligadas ao desenvolvimento de sua personalidade, seja no âmbito pessoal, seja no social, culminando numa renúncia involuntária às atividades habituais ou pretendidas, comprometedora das esferas existenciais humanas. ${ }^{17}$

Assim, logo se percebe que, para o razoável exercício, pelo indivíduo, de suas variadas atividades existenciais, prescinde-se da colaboração social como um todo, valendo lembrar que o artigo $5^{\circ}, \mathrm{X}$, da Constituição Federal estabelece que "são invioláveis a intimidade, a vida privada, a honra e a imagem das pessoas, assegurado o direito a indenização pelo dano material ou moral decorrente de sua violação".

Anote-se que o Poder Judiciário, conforme exemplifica o julgado abaixo colacionado advindo da seara trabalhista, vem reconhecendo o dano existencial e condenando ofensor à reparação:

INDENIZAÇÃO POR DANO EXISTENCIAL. JORNADA DE TRABALHO EXTENUANTE. O dano existencial consiste em espécie de dano extrapatrimonial cuja principal característica é a frustração do projeto de vida pessoal do trabalhador, impedindo a sua efetiva integração à sociedade, limitando a vida do trabalhador fora do ambiente de trabalho e o seu pleno desenvolvimento como ser humano, em decorrência da conduta ilícita do empregador. O Regional afirmou, com base nas provas coligidas aos autos, que a reclamante laborava em jornada de trabalho extenuante, chegando a trabalhar 14 dias consecutivos sem folga compensatória, laborando por diversos domingos. Indubitável que um ser humano que trabalha por um longo período sem usufruir do descanso que lhe é assegurado, constitucionalmente, tem sua vida pessoal limitada, sendo despicienda a produção de prova para atestar que a conduta da empregadora, em exigir uma jornada de trabalho deveras extenuante, viola o princípio fundamental da dignidade da pessoa huma-

16 Artigos $5^{\circ}$, XIII $, 6^{\circ}, 7^{\circ}, 170$, Constituição Federal de 1988

17 ALMEIDA, Greicy Fraga. Dano existencial ou dano ao projeto de vida? Disponível em: $<$ https://www.uniritter. edu.br/files/sepesq/arquivos_trabalhos/3612/662/752.pdf> 
na, representando um aviltamento do trabalhador. $\mathrm{O}$ entendimento que tem prevalecido nesta Corte é de que o trabalho em sobrejornada, por si só, não configura dano existencial. Todavia, no caso, não se trata da prática de sobrelabor dentro dos limites da tolerância e nem se trata de uma conduta isolada da empregadora, mas, como afirmado pelo Regional, de conduta reiterada em que restou comprovado que a reclamante trabalhou em diversos domingos sem a devida folga compensatória, chegando a trabalhar por 14 dias sem folga, afrontando assim os direitos fundamentais do trabalhador. Precedentes. Recurso de revista conhecido e desprovido. (TST - RR: 10347420145150002, Relator: José Roberto Freire Pimenta, Data de Julgamento: 04/11/2015, $2^{\text {a }}$ Turma, Data de Publicação: DEJT $13 / 11 / 2015)$

E conforme será destacado prioritariamente ao final, também é possível localizar julgados que prestigiam os abusos às atividades existenciais humanas nas relações de consumo, que se engloba no tema geral.

Sob outro aspecto, conste que, consoante o tópico anterior, o exercício de tais atividades é estritamente condicionado ao tempo, já que é justamente este o fator que viabiliza o fazer. O desvio produtivo consubstancia ato ilícito também por ensejar ofensa às atividades existenciais da pessoa humana, ponto que será desenvolvido nos tópicos subsequentes.

\section{DA INOBSERVÂNCIA, PELO FORNECEDOR, DO DEVER DE BOM ATENDIMENTO}

O Código de Defesa do consumidor estabelece como princípio o dever de qualidade dos produtos e serviços postos no mercado (art. $4^{\circ}, \mathrm{V}$ ). De toda forma, é certo que ao fornecedor incumbe o bom atendimento, preceito manifestamente presente na legislação consumerista e implícito em seus mais diversos dispositivos, situando no espírito da norma.

Levando em conta tais preceitos, Marcos Dessaune delimita que

(...) o fornecedor deve oferecer as seguintes utilidades no mercado, por intermédio do seu produto final: a satisfação das necessidades, desejos e expectativas do consumidor; preservação dos recursos naturais de uso comum, paralelamente à minimização dos impactos ambientais negativos decorrentes da atuação dele (fornecedor); promoção do bem-estar do consumidor, contribuição para existência digna do consumidor; maximização qualitativa das utilidades individuais que já oferece. ${ }^{18}$

Todavia, uma vez sendo constantes as situações de mau atendimento nas relações de consumo, tais preceitos parecem se distanciar da vida prática - como se diz, situando apenas como letra morta. Nesse sentido Rene Edney Soares Loureiro e Héctor Valverde Santana defende que:

São comuns situações constrangedoras, vexatórias, desproporcionais do consumidor esperar em pé, por período de duas ou mais horas na fila de uma instituição bancária que, por contenção de gastos, reduziu drasticamente o número de funcionários para atendimento ao público; ser compelido a proferir incontáveis ligações para as operadoras de telefonia móvel, com a perda de preciosas horas do dia, com o simples intuito de cancelar algum tipo de serviço ou solicitar alguma providência, sem contudo, obter êxito; ser for-

18 DESSAUNE, Marcos. Teoria aprofundada do desvio produtivo do consumidor: o prejuízo do tempo desperdiçado e da vida alterada. 2. ed. Vitória, 2017. p. 62. 
çado a ligar insistentemente para os sistemas de call center e SACs com a finalidade de cancelar o serviço de tevê por assinatura, sem entretanto, alcançar o fim; ser obrigado a se deslocar até a loja ou autorizada, por diversas vezes, com a finalidade de solucionar o defeito ou vício de um produto ou serviço recém adquirido (...) ser vítima do jogo do empurra dos atendentes e operadoras de serviço de internet com claro intuito de ganhar tempo e evitar o cancelamento do serviço, enquanto chega a próxima fatura $(. . .)^{19}$

Assim, não obstante ser fruto de uma gestão deficitária (fortuitos internos), conforme defende Marcos Dessaune, o mau atendimento pode se qualificar pela intencionalidade enquanto forma de exploração abusiva do consumidor. Sobre esse ponto, o autor explana que:

A comprovação da intenção maliciosa desse tipo de conduta danosa, envolvendo especificamente operadoras de telefonia, veio à tona em uma matéria-denúncia veiculada em 06-10-2011 pelo jornal Bom Dia Brasil, da TV Globo Minas, sob o título 'Atendentes de telemarketing relatam técnicas para tentar enganar clientes'. De acordo com a reportagem disponível no portal G1 Minas Gerais, tais ‘técnicas para enganar clientes' são estabelecidas pelas próprias empresas de telefonia denunciadas, que as ensinam aos atendentes de telemarketing e deles cobram resultados por intermédio dos seus chefes imediatos. ${ }^{20}$

E apesar dos exemplos citados mais se alinharem à fase pós-contratual e contratual, o mau atendimento também é corriqueiro na fase pré-contratual e até mesmo de modo extracontratual, tal como a prática abusiva prevista no artigo 39, III, do $\mathrm{CDC}^{21}$.

Anote-se que, tais condutas, por óbvio, destoam completamente dos critérios de boa-fé objetiva, previsto no artigo $4^{\circ}$, III, do CDC, consubstanciando ato ilícito também nesse aspecto.

Sobre esse ponto, utilizando novamente as ponderações de Rene Edney Soares Loureiro e Héctor Valverde Santana, consigna-se que:

Os serviços de pronto atendimento, autorizadas, SACs, bem como os diversos meios físicos e virtuais de atendimento ao consumidor, exige-se a internalização das externalidades consumeristas negativas, obrigando o fornecedor a internalizar os custos sociais externos, a fim de que o custo resultante da fabricação, disponibilização, venda ou fornecimento de produtos e serviços seja por ele assumido no custo da produção, devendo agir, investir, implantar e efetivar mecanismos idôneos de solução de problemas de produtos e serviços com escopo de diminuir, eliminar ou neutralizar o desperdício injusto e ilegítimo do tempo por parte do consumidor. ${ }^{22}$

Frisa-se que, mesmo se o mau atendimento derivar de fortuitos internos, primordialmente

19 LOUREIRO, Rene Edney Soares; SANTANA, Héctor Valverde. Dano moral e responsabilidade objetiva do fornecedor pela perda do tempo produtivo do consumidor. Revista de Direito do Consumidor, São Paulo, v. 106, ano 25, p. 357-378, jul.-ago. 2016. p. 360.

20 DESSAUNE, Marcos. Teoria aprofundada do desvio produtivo do consumidor: o prejuízo do tempo desperdiçado e da vida alterada. 2. ed. Vitória, 2017. p. 81.

21 DESSAUNE, Marcos. Teoria aprofundada do desvio produtivo do consumidor: o prejuízo do tempo desperdiçado e da vida alterada. 2. ed. Vitória, 2017. p. 65.

22 LOUREIRO, Rene Edney Soares; SANTANA, Héctor Valverde. Dano moral e responsabilidade objetiva do fornecedor pela perda do tempo produtivo do consumidor. Revista de Direito do Consumidor, São Paulo, v. 106, ano 25, p. 357-378, jul.-ago. 2016. p. 373. 
quando o fornecedor exerce atividade de risco, há uma forte tendência pela inadmissibilidade do referido motivo enquanto excludente de responsabilidade civil, haja vista também que, conforme os artigos 12 e 14 do CDC, salvo pontuais exceções, sua responsabilidade civil é objetiva. Nesse caso, serve como exemplo a responsabilização das companhias aéreas quando, por decorrência de fatores meteorológicos, o serviço não é prestado ou o consumidor é mal atendido nessas hipóteses. $^{23}$

Ademais, ainda no que tange o reconhecimento de falha na prestação do serviço e consequente direito à indenização proveniente de fortuito interno nas relações de consumo, é evidente que a não exclusão da responsabilidade civil do fornecedor presta homenagem ao princípio da reparação integral dos danos, previsto no artigo $6^{\circ}$, VI, do CDC.

Em se tratando do tema atendimento ao consumidor, o Poder Judiciário é bastante conhecedor de suas mazelas, vez que os problemas não resolvidos administrativamente muitas vezes ganham forma de demanda judicial. É certo que grande parte das ações advindas de relações de consumo são oriundas do mau atendimento. É o que se depreende do levantamento feito pelo $O$ Globo, o qual indica que dos 90 milhões de processos em que são discutidas questões de consumo, cerca de 40 milhões dizem respeito ao setor bancário e de telefonia, sendo a ineficiência dos serviços e o mau atendimento ao cliente (call centers e SACs) os principais motivos que impulsionaram os consumidores a ingressarem com as ações ${ }^{24}$.

No que diz respeito ao Tribunal de Justiça do Estado do Paraná (TJ-PR), mormente pelos enunciados de suas Turmas Recursais, nitidamente se constata que os mecanismos de atendimento ao consumidor realmente são falhos e burocráticos, sabotando o tempo útil (ou livre) do consumidor, mesmo porque os referidos enunciados somente surgem propriamente pela repetição de julgados de determinada matéria, ou seja, da recorrência de casos similares que levam a formação de determinado entendimento acerca do assunto.

A título de exemplo, cita-se os supraditos enunciados das Turmas Recursais do TJ-PR que mais se relacionam ao mau atendimento do consumidor e a perda de seu tempo útil ou livre:

Enunciado n. 1.6 - Call-center ineficiente - dano moral: Configura dano moral a obstacularização, pela precariedade e/ou ineficiência do serviço de call center, por parte da empresa de telefonia, como estratégia para não dar o devido atendimento aos reclamos

23 APELAÇ̃̃O CIIVEL E RECURSO ADESIVO. ATRASO VOO. DANOS MORAIS. CONDIČ̃̃ES CLIMÁTICAS. APELAÇÃO CÍVEL. 1. ATRASO DE VOO EM RAZÃO DE MAU TEMPO. FORTUITO INTERNO QUE NÃO AFASTA O DEVER DE INDENIZAR DA COMPANHIA AÉREA. 2. DANOS MORAIS. CONFIGURACC̃̃O. ATRASO DO VOO E DEFEITO NOS SERVIÇOS PRESTADOS PELA COMPANHIA AÉREA QUE SÃO HÁBEIS A GERAR DANOS MORAIS (DANOS IN RE IPSA). (...) (TJ-PR - $8^{\mathrm{a}}$ C. Cível - AC - 1384893-2 - Região Metropolitana de Londrina - Foro Central de Londrina - Rel.: Francisco Eduardo Gonzaga de Oliveira - Unânime - J. 17.09.2015)

(...) PROBLEMAS METEOROLÓGICOS QUE SE INSEREM NO RISCO DO NEGÓCIO E FORTUITO INTERNO, INCAPAZ DE AFASTAR O NEXO DE CAUSALIDADE E EXCLUIR A RESPONSABILIDADE CIVIL DA RÉ. (...) (TJ-RJ - RI: 02041834220118190001 RJ 0204183-42.2011.8.19.0001, Relator: TIAGO HOLANDA MASCARENHAS, Terceira Turma Recursal, Data de Publicação: 04/07/2012 12:50)

24 Disponível em: [http://oglobo.globo.com/economia/defesa-do-consumidor/acoes-de-consumo-somam-quasemetade-dos-90-milhoes-de-processos-no-judiciario-10266371]. Acesso em: 25/05/2017 
do consumidor. ${ }^{25}$

Enunciado n. 2.7- Fila de banco - dano moral: A espera em fila de agência bancária, em tempo excessivo, caracteriza falha na prestação de serviço e enseja reparação por danos morais. ${ }^{26}$

Portanto, restou evidente que o mau atendimento ao consumidor, não obstante transgredir alguns dos mais basilares preceitos do CDC, viola os direitos da personalidade, funcionando também como fator causador do desvio produtivo nas relações de consumo.

\section{DO DESVIO PRODUTIVO}

Como visto, sobretudo na contemporaneidade, o tempo constitui bem jurídico precioso para o ser humano, devendo ser tutelado, dentre outros vieses, pelo fato de ser justamente o componente capaz de viabilizar o exercício das atividades existenciais da pessoa humana, atividades estas relevantes para o alcance ou manutenção da dignidade enquanto princípio fundamental da atual Constituição Federal.

Por outro lado, situando-se inevitavelmente numa sociedade de consumo, que inclusive perfaz atividade existencial do indivíduo, se mantém o consumidor, enquanto vulnerável, submetido às tratativas junto aos fornecedores de produtos e serviços para satisfação de suas necessidades - muitas vezes essenciais - e anseios em geral. Todavia, consoante se abordou anteriormente, muitas vezes o atendimento é deficitário.

Recorde-se que, conforme delineado oportunamente, não raras vezes o mau atendimento ao consumidor se inclui em estratégia de grandes empresas para obstaculizar o cancelamento do serviço ou resolver eventuais reclames de modo geral.

De outro giro, há também determinados fornecedores que não são dotados de meios adequados e suficientes para prestar um bom atendimento, o que apesar de não repercutir negativamente no campo da boa-fé objetiva, não deixa de ser ato ilícito indenizável pelos outros aspectos já esmiuçados.

Portanto, como bem aduz Marcos Dessaune:

Independentemente do porte do fornecedor, do seu grau de culpabilidade e do resultado que seu ato alcançar, a conduta de tentar atenuar, impossibilitar ou exonerar sua responsabilidade por problemas de consumo configura a prática abusiva (gênero) vedada pelos arts. 25, 39, V e 51, I e IV, do CDC. Ao se esquivar de resolver o problema primitivo em prazo compatível com a real necessidade do consumidor, o fornecedor consuma tal prática abusiva e gera para o consumidor duas novas alternativas de ação, que são indesejadas:

$\overline{25 \text { Disponível em }}:<$ https://www.tjpr.jus.br/enunciados-turmas-recursais $>$. Acesso em: 04/05/2017

26 Disponível em: < https://www.tjpr.jus.br/enunciados-turmas-recursais>. Acesso em: 04/05/2017 
assumir o prejuízo ou tentar, ele mesmo, solucionar a situação lesiva. ${ }^{27}$

Assim, diante do mau atendimento, a depender do problema em jogo, em certas ocasiões o consumidor opta até mesmo por não investir seu tempo e seu ânimo na resolução, como ocorre, exemplificando, nos pequenos acréscimos em faturas. Em outras, lança-se à resolução do problema, muitas vezes criado pelo próprio fornecedor, enfrentando mecanismos de atendimento deficitários e, sem embargo de outras más repercussões nos direitos da personalidade, acabando por sofrer o desvio produtivo.

No primeiro caso, evidentemente, o fornecedor lucra com sua deficiência, o que é inadmissível. No segundo, o consumidor arca indevidamente um desvio produtivo, o que de igual forma é inaceitável. Dessa maneira, o referido dano é patrocinado primordialmente pelos ineficientes mecanismos de atendimento ao consumidor, extravasando as raias da razoabilidade e dando lugar à irritação, à frustração, à sensação de descaso.

Em se falando de raias da razoabilidade, ponto este ligado ao que muitas vezes recebe o título de "mero aborrecimento" pelo Poder Judiciário na resolução de demandas, consigne-se desde já que o desvio produtivo não se insere nos aborrecimentos inevitáveis e inerentes ao próprio convívio social, mas decorre exclusivamente da falha na prestação do serviço pelo fornecedor sobretudo na prestação do atendimento em fase contratual e pós-contratual.

Desse modo, é um problema na seara de consumo criado e municiado exclusivamente pelo fornecedor, nada tendo a ver com as insatisfações derivadas naturalmente da vida em sociedade. A perda involuntária do tempo, portanto, advém unicamente da prestação do serviço.

Ademais, pontua Vitor Vilela Guglinski que:

Segundo o entendimento jurisprudencial até o momento dominante, a perda involuntária do tempo impingida pelo fornecedor que presta um mau atendimento ao consumidor reflete negativamente em sua esfera anímica, passando o ofendido a experimentar sentimentos humanos desagradáveis, como: frustração, intranquilidade, angústia, irritação etc. $^{28}$

Tudo indica que o desvio produtivo se situa enquanto dano de natureza moral, já que seus desdobramentos incidem negativamente sob os direitos da personalidade.

\section{DA NATUREZA DO DANO}

Quando se fala em dano, mormente nas relações de consumo, deve-se levar em consideração o princípio da reparação integral, previsto no artigo $6^{\circ}$, VI, do CDC.

No tema em estudo, tendo em vista que o desvio produtivo resulta em ofensa aos direitos da personalidade do consumidor, parece mais acertado o classificar como dano moral (ou extrapa-

27 DESSAUnE, Marcos. Teoria aprofundada do desvio produtivo do consumidor: o prejuízo do tempo desperdiçado e da vida alterada. 2. ed. Vitória, 2017. p. 272.

28 GUGLINSKI, Vitor. O dano temporal e sua reparabilidade: aspectos doutrinários e visão dos tribunais. Revista de Direito do Consumidor, v. 99, p. 125 - 156, maio-jun. 2015. p. 149. 
trimonial ou imaterial), que tem respaldo no ordenamento jurídico brasileiro a partir do artigo $5^{\circ}$, V e X, da Constituição Federal de 1988, dispondo o seguinte:

Art. $5^{\circ}$ Todos são iguais perante a lei, sem distinção de qualquer natureza, garantindo-se aos brasileiros e aos estrangeiros residentes no País a inviolabilidade do direito à vida, à liberdade, à igualdade, à segurança e à propriedade, nos termos seguintes:

V - é assegurado o direito de resposta, proporcional ao agravo, além da indenização por dano material, moral ou à imagem;

X - são invioláveis a intimidade, a vida privada, a honra e a imagem das pessoas, assegurado o direito a indenização pelo dano material ou moral decorrente de sua violação

Nesse tocante, Flávio Tartuce salienta que:

A tese pela reparabilidade dos danos imateriais tornou-se pacífica com a Constituição Federal de 1988. Antes disso, era tido como impossível aceitar a reparação do dano moral, eis que doutrina e jurisprudência tinham dificuldades na visualização de sua determinação e quantificação. Com a Constituição Federal de 1988 houve uma grande evolução quando tema, que até mergulhou em outros âmbitos. ${ }^{29}$ (TARTUCE, Flávio. 2016. p. 409)

Além do notório respaldo constitucional, o direito à indenização por danos morais também é consagrado pelos artigos 186 e 927 do Código Civil e pelo artigo 6º VI, do CDC, o mesmo que estabelece o já mencionado princípio da reparação integral.

Em relação ao conceito do dano moral, dentre os diversos debates e posicionamentos doutrinários, cita-se lição de Humberto Theodoro Júnior, "pode-se afirmar que são danos morais os ocorridos na esfera da subjetividade, ou no plano valorativo da pessoa na sociedade, alcançando os aspectos mais íntimos da personalidade humana". ${ }^{30}$

Sérgio Cavalieri Filho, por sua vez, anota que:

À luz da Constituição vigente, podemos conceituar o dano moral por dois aspectos distintos. Em sentido estrito, dano moral é violação do direito à dignidade. E foi justamente por considerar a inviolabilidade da intimidade, da vida privada, da honra e da imagem corolário do direito à dignidade que a Constituição inseriu em seu art. $6^{\circ}, \mathrm{V}$ e $\mathrm{X}$, a plena reparação do dano moral. ${ }^{31}$

Com essa lição, uma vez que dentre outros desprazeres gerados, o desvio produtivo ofende as atividades existenciais do indivíduo que, como visto, ligam-se (ou promovem) à dignidade da pessoa humana, revela-se prudente também por este viés classificá-lo como um dano de ordem moral.

E quanto ao sentido amplo, pontua o mesmo autor que:

Nessa categoria incluem-se também os chamados novos direitos da personalidade: a imagem, o bom nome, a reputação, sentimentos, relações afetivas, aspirações, hábitos, gostos

29 TARTUCE, Flávio. Direito Civil: direito das obrigações e responsabilidade civil. 11. ed. Rio de Janeiro: Forense, 2016. p. 409.

30 THEODORO JÚNIOR, Humberto. Dano moral. 8. ed. Rio de Janeiro: Forense, 2016. p. 2.

31 CAVALIERI FILHO, Sergio. Programa de direito do consumidor. 3. ed. São Paulo: Atlas, 2011. p. 80-81. 
(...). Em suma, (...) podem ser realizados em diferentes dimensões e também podem ser violados em diferentes níveis. Resulta daí que o dano moral, em sentido amplo, envolve esses diversos graus de violação dos direitos da personalidade, abrange todas as ofensas à pessoa, considerada esta em suas dimensões individual e social, ainda que sua dignidade não seja arranhada. ${ }^{32}$

Entretanto, também não se confere dificuldade em associar os malefícios do desvio produtivo em relação aos chamados novos direitos da personalidade, vez que o autor cita, por exemplo, o abuso às aspirações do indivíduo.

De outro giro, conforme adverte Vitor Vilela Guglinski:

Atualmente, doutrina e jurisprudência vêm se posicionando no sentido de que, para que o dano moral reste configurado, não é necessário o desencadeamento de sentimentos humanos negativos. A propósito, a questão foi objeto de debates na V Jornada de Direito Civil, promovida pelo Conselho da Justiça Federal (CFJ) em parceria com o Superior Tribunal de Justiça (STJ), ocasião em que foi aprovado o Enunciado $445 .^{33}$

Tal posicionamento lembra os danos morais in reipsa, isto é, aqueles que prescindem de efetiva demonstração de ofensa aos direitos da personalidade, presumindo-se, de determinada ação do ofensor, que o dano foi gerado, como por exemplo nos casos de inclusão indevida em cadastros restritivos de crédito. Nesse sentido é o enunciado 1.1 das Turmas Recursais do TJ-PR. ${ }^{34}$

Outrossim, sobre o assunto, ilustra Milena Donato Oliva que:

Em razão da natureza imaterial do dano moral e da sua constante associação ao sofrimento da vítima, o recurso expediente in reipsa tem parecido necessário em numerosas situações. Colhe-se dos aludidos precedentes que, diante de certos acontecimentos, não seria razoável exigir a prova do dano moral, vez que dos fatos seria inequívoco o dissabor experimentado pela vítima. Como se percebe, o mecanismo in reipsa tem por escopo facilitar a reparação dos danos morais, pois objetiva afastar discussões que, na prática, poderiam deixar a vítima sem ressarcimento. ${ }^{35}$

Uma vez vigorantes nas relações de consumo os princípios da reparação integral e vulnerabilidade do consumidor, transparece adequado a dispensa, em situações pontuais, da demonstração do efetivo prejuízo moral sofrido pelo consumidor, principalmente quando não é difícil presumi-lo a partir da qualificação do ato lesivo. Complementando, vale-se novamente das lições de Milena Donato Oliva:

Na atual sociedade de consumo, em que há lesões massificadas e repetitivas, mostra-se

32 CAVALIERI FILHO, Sergio. Programa de direito do consumidor. 3. ed. São Paulo: Atlas, 2011. p. 80-81.

33 GUGLINSKI, Vitor. O dano temporal e sua reparabilidade: aspectos doutrinários e visão dos tribunais. Revista de Direito do Consumidor, v. 99, p. 125 - 156, maio-jun. 2015. p. 149.

34 Dívida paga - inscrição/manutenção - dano moral: A inscrição e/ou manutenção de dívida paga em órgãos de restrição ao crédito configura dano moral.

(Disponível em: <https://www.tjpr.jus.br/enunciados-turmas-recursais>)

35 OLIVA, Milena Donato. Dano moral e inadimplemento contratual nas relações de consumo. Revista de Direito do Consumidor, v. 93, p. 13-28, maio-jun. 2014. p. 16. 
meritória a atitude dos tribunais no sentido de identificar certas condutas com aptidão lesiva a interesses extrapatrimoniais e, conseguintemente, potencialmente ensejadores de dano moral. Por outro lado, não se pode exasperar a valoração abstrata do ato em detrimento das peculiaridades do caso concreto, de modo a se comprometer a ampla reparação que deve ser assegurada ao consumidor. ${ }^{36}$

Como bem pontuado, não se pode esquecer que em determinados casos se faz presente lesividade mais extensa que justifica o arbitramento mais elevado da indenização. Portanto, deve o conceito in reipsa ser aplicado em benefício e não em prejuízo à reparação integral. Para tanto, mesmo nesses casos de lesões massificadas e repetitivas, incumbe ao magistrado observar as peculiaridades do caso concreto.

A propósito, o dano em estudo, desvio produtivo do consumidor, muitas vezes se caracteriza em virtude de uma ilicitude principal do fornecedor. Por exemplo, quando, na tentativa de resolver algum defeito na prestação do serviço, é preciso se dispensar um tempo absurdo no call center. Justamente por isso é que deve o magistrado observar as peculiaridades do caso concreto no arbitramento da reparação pelo dano extrapatrimonial.

Ainda levando em consideração o caso hipotético lançado, não seria nem remotamente razoável, à luz do princípio da reparação integral, que o dano moral pela falha na prestação do serviço abrangesse os danos pelo desvio produtivo e pelo call center ineficiente. Por mais que estejam em cadeia, é capital que as ilicitudes em questão pelo menos funcionem como fatores de aumento do valor da reparação, sob pena de desprestigiar o previsto no artigo $6^{\circ}$, VI, do CDC e, de antemão, encorajar que o fornecedor alimente estratégia consistente em obstaculizar a resolução dos reclames do consumidor, conforme já abordado.

Uma vez adentrando na questão do valor indenizatório, se faz pertinente colacionar as lições de Humberto Theodoro Júnior, que assim define:

O problema mais sério suscitado pela admissão da reparabilidade do dano moral reside na quantificação do valor econômico a ser reposto ao ofendido. Quando se trata de dano material, calcula-se exatamente o desfalque sofrido no patrimônio da vítima, e a indenização consistirá no seu exato montante. Mas quando o caso é de dano moral, a apuração do quantum indenizatório de complica porque o bem lesado (a honra, o sentimento, o nome etc.) não se mede monetariamente, ou seja, não tem dimensão econômica patrimonial. ${ }^{37}$

Portanto, o que se difunde na jurisprudência é que o arbitramento do valor da indenização por dano moral deve ser suficiente a compensar o lesado e punir o ofensor. Não obstante, deve-se levar em consideração o grau de reprovação da conduta, a repercussão da ofensa e a posição social das partes, calcando-se ainda nos critérios da razoabilidade e proporcionalidade que implicitamente se fazem presentes na Constituição Federal de 1988. Nesse sentido:

AÇÃO DE INDENIZAÇÃO - NEGATIVAÇÃO INDEVIDA - CRITÉRIOS PARA FI-

XAÇÃO - QUANTUM INDENIZATÓRIO (...) Ao fixar valor da indenização deve-se ter 36 OLIVA, Milena Donato. Dano moral e inadimplemento contratual nas relações de consumo. Revista de Direito do Consumidor, v. 93, p. 13-28, maio-jun. 2014. p. 17.

37 THEODORO JÚNIOR, Humberto. Dano moral. 8. ed. Rio de Janeiro: Forense, 2016. p. 35. 
em conta as condições do ofendido, do ofensor e do bem jurídico lesado. A indenização deve proporcionar à vítima satisfação na justa medida do abalo sofrido, sem enriquecimento sem causa, produzindo no causador do mal impacto suficiente para dissuadi-lo de igual e semelhante atentado. (...) (TJ-MG - AC: 10512120033679001 MG, Relator: Nilo Lacerda, Data de Julgamento: 07/08/2013, Câmaras Cíveis / 12ª CÂMARA CÍVEL, Data de Publicação: 14/08/2013)

Ademais, considerando que o artigo 926 do Código de Processo Civil determina que "os tribunais devem uniformizar sua jurisprudência e mantê-la estável, íntegra e coerente", defende Humberto Theodoro Junior que:

Impõe-se a rigorosa observância dos padrões adotados pela doutrina e jurisprudência, inclusive dentro da experiência registrada no direito comparado para evitar-se que as ações de reparação de dano moral se transformem em expedientes de extorsão ou de espertezas maliciosas e injustificáveis. ${ }^{38}$

Esses são parâmetros que o magistrado pode (deve) se apegar para fixação do quantum indenizatório, é plenamente viável seu correto arbitramento em atendimento às peculiaridades do caso concreto.

\section{CONSIDERAÇÕES FINAIS}

O Direito visa proteger interesses que devem ser juridicamente relevantes, sob pena de não merecer proteção jurídica. Com base nessas premissas, o presente estudo defendeu que o tempo torna-se um bem jurídico na contemporaneidade. No decorrer do texto, diversas conclusões foram tomadas no intuito de fazer uma construção lógica para o que defendemos. Todavia, listaremos algumas conclusões que são essenciais para o trabalho ora defendida:

1. É incontroversa, mormente na contemporaneidade, a relevância do tempo, constituindo bem juridicamente protegido.Isso pois, conforme se demonstrou nos tópicos inaugurais, não obstante exercer funções vitais dentro do mundo jurídico, é justamente o fator que viabiliza o desempenho das atividades existenciais humanas. Desse modo, sua proteção está intrinsicamente ligada à tutela da dignidade - princípio orientador vigente no ordenamento jurídico pátrio.

2. Pela importância do tempo e do razoável exercício das atividades existenciais, é evidente que o fornecedor, quando deixa de observar seu dever de bom atendimento (art. $4^{\circ}, \mathrm{V}, \mathrm{CDC}$ ), valese de estratégias comerciais desleais para não prestar o devido suporte aos reclames do consumidor, ou ainda negligencia a disponibilização de mecanismos de atendimento adequados,exigindoque o consumidor - parte vulnerável da relação de consumo - desvie de suas competências ou atividades pretendidas para tentar resolver defeitos da prestação do serviço, está cometendo ilicitudes consumeristas seja por ferir os princípios basilares instituídos pelo CDC, seja por ofender os

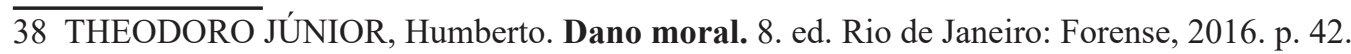


direitos da personalidade.

3. Portanto, conforme abordou-se no quarto tópico, merece atenção a teoria do desvio produtivo, que não se confunde com o que não raramente recebe o título de "mero aborrecimento" pelo Poder Judiciário na resolução de demandas de consumo, vez que não decorre de aborrecimentos inerentes à vida em sociedade, mas surge exclusivamente da falha na prestação do serviço pelo fornecedor.

4. Assim, conforme se explanou no tópico final, em se tratando o desvio produtivo de um dano ofensivo aos direitos da personalidade, é prudente classificá-lo como dano moral (ou extrapatrimonial ou imaterial), previsto inicialmente no artigo $5^{\circ}$, V e X, da Constituição Federal de 1988, devendo, quando evidenciado, justificar indenização(ou sua majoração) em tutela à dignidade do consumidor, devendo ser arbitrada conforme as peculiaridades do caso concreto em vistas à prestigiar o princípio da reparação integral consagrado no artigo $6^{\circ}, \mathrm{IV}$, do CDC e, de antemão, coibir tais práticas abusivas por parte do fornecedor.

\section{REFERÊNCIAS}

ARAUJO JUNIOR. Antônio Dinei Aguiar; CASTROVIEJO, Tomas Angel. A influência do tempo no sistema jurídico. Disponível em: $<$ https://uspdigital.usp.br/siicusp/ dOnlineTrabalhoVisualizarResumo?numeroInscricaoTrabalho $=3456 \&$ numeroEdicao $=18<\mathrm{https}: / /$ uspdigital.usp.br/siicusp/ cdOnlineTrabalhoVisualizarResumo?numeroInscricaoTrabalho=3456\&numeroEdicao $=18>$. Acesso em 30 out. 2017.

ALMEIDA, Greicy Fraga. Dano existencial ou dano ao projeto de vida? Disponível em: $<$ https:// www.uniritter.edu.br/files/sepesq/arquivos_trabalhos/3612/662/752.pdf>

CAVALIERI FILHO, Sergio. Programa de direito do consumidor. 3. ed. São Paulo: Atlas, 2011.

COCKERELL, Lee. A magia do gerenciamento do tempo. Tradução de Cristina Yamagami. São Paulo: Benvirá, 2016.

DESSAUNE, Marcos. Teoria aprofundada do desvio produtivo do consumidor: o prejuízo do tempo desperdiçado e da vida alterada. 2. ed. Vitória, 2017.

GARCIA, Leonardo de Medeiros. Direito do consumidor: Código comentado e jurisprudência. 7. ed. Niterói: Impetus, 2011.

GUGLINSKI, Vitor. O dano temporal e sua reparabilidade: aspectos doutrinários e visão dos tribunais. Revista de Direito do Consumidor, v. 99, p. 125 - 156, maio-jun. 2015.

LOUREIRO, Rene Edney Soares; SANTANA, Héctor Valverde. Dano moral e responsabilidade objetiva do fornecedor pela perda do tempo produtivo do consumidor. Revista de Direito do Consumidor, São Paulo, v. 106, ano 25, p. 357-378, jul.-ago. 2016. 
OLIVA, Milena Donato. Dano moral e inadimplemento contratual nas relações de consumo.

Revista de Direito do Consumidor, v. 93, p. 13-28, maio-jun. 2014.

TARTUCE, Flávio. Direito Civil: direito das obrigações e responsabilidade civil. 11. ed. Rio de Janeiro: Forense, 2016.

THEODORO JÚNIOR, Humberto. Dano moral. 8. ed. Rio de Janeiro: Forense, 2016.

Como citar: DOMINGUES, Jean Guilherme Capeli. BRASILINO, Fabio Ricardo Rodrigues. A teoria do desvio produtivo e a proteção dos direitos da personalidade do consumidor. Revista do Instituto de Direito Constitucional e Cidadania, Londrina, v. 3, n. 1, p. 190-208, jan/jun. 2018.

Recebido em: 11/04/2018

Aprovado em: 20/05/2018 